\title{
A New Coated Wire Selective Electrode for Quetiapine in Biological and Pharmaceutical Analysis
}

\author{
Hassan Arida ${ }^{1,2, *}$, Majed Al robaian ${ }^{1}$, Mena Elbeshlawy ${ }^{3}$, Amjad Fataftah $^{4}$, Ghalib AL-Sllami $^{5}$ \\ ${ }^{1}$ Pharmacy College, Taif University, 888-Taif, Saudi Arabia \\ ${ }^{2}$ Hot Laboratories Center, Atomic Energy Authority, 13759-Cairo, Egypt \\ ${ }^{3}$ Chemistry Department, College for Girls, Ain Shams University, Heliopolis, Cairo, Egypt \\ ${ }^{4}$ Chem. Dep., College of Science and General Studies, Alfaisal Univ., 11533-Riyadh, Saudi Arabia \\ ${ }^{5}$ Forensic Chemistry Department, Forensic Sciences College, Naif Arab University for Security \\ Sciences, Riyadh, Saudi Arabia \\ *E-mail: aridaha@hotmail.com
}

doi: $1020964 / 2017.05 .76$

Received: 27 December 2016 / Accepted: 19 March 2017 / Published: 12 April 2017

Fabrication of organic PVC membrane based coated wire electrode for sensitive, fast, precise and simple determination of quetiapine in pharmaceutical formulation and urine samples is demonstrated. The new electrode was constructing using quetiapine : tetraphenyl borate ion pair complex as electroactive material, PVC as supporting matrix, 2-nitrophenyl octyl ether as mediator of solvent and potassium tetrakis (4-chlorophenyl) borate as lipophilic additive. The electrode provides Nernstian response $\left(57 \pm 0.2 \mathrm{mV} /\right.$ decade) over a wide concentration range of $1 \times 10^{-5}$ to $1 \times 10^{-2} \mathrm{~mol} \mathrm{~L}^{-1}$ of quetiapine with lower limit of detection $\left(3.2 \times 10^{-6} \mathrm{~mol} \mathrm{~L}^{-1}\right)$, fast response time (less than ten seconds) and relatively long life span (30 days). Stability with verification of the suitability of the electrode to be applied in the analysis of drug quality control in pharmaceutical and biological (urine) samples was assessed. The results obtained revealed a good agreement with those obtained from independent standard method (high performance liquid chromatography). In the pharmaceutical analysis application, the recovery of the quetiapine selective electrode ranging from 98.83 to $103.27 \%$, the confidence of the two methods is $95 \%$ and the standard deviation is 2.49 . While in the biological analysis of urine, the recovery of the electrode with respect to the standard method ranging from 96.45 to $97.48 \%$, the confidence is $95 \%$ and the standard deviation is 1.48 .

Keywords: Quetiapine; PVC membrane; coated wire electrode; pharmaceutical analysis; biological applications.

\section{FULL TEXT}


(C) 2017 The Authors. Published by ESG (www.electrochemsci.org). This article is an open access article distributed under the terms and conditions of the Creative Commons Attribution license (http://creativecommons.org/licenses/by/4.0/). 